Published as: Visscher, K. (2006), "Capturing the competence of management consulting work", Journal of Workplace Learning, 18(4), pp.248-260

\title{
Capturing the competence of management consulting work
}

\author{
Klaasjan Visscher \\ School of M anagement and $\mathrm{G}$ overnanœ, U niversity of T wente \\ k.visscher@ utwente.nl
}

\section{Abstract}

\section{Purpose of this paper}

The purpose of this article is to assess whether the effort of consulting firms and branch organizations to establish a shared and standardized methodology as a means to professionalize consulting and as a standard for training is possible and sensible.

\section{Design/ methodology/ approach}

A survey was conducted among D utch management consultants, which explored their ways of working and their ways of learning.

\section{Findings}

The study shows that efforts to develop a shared and standardized phase-model methodology do not seem to be effective. Instead of following phase-models, consultants appear to be improvising bricoleurs, tailoring their ways of working to specific situations, and using broad, heterogeneous and partly implicit repertoires, which are built through mainly through action-learning. This requires another kind of methodology and another kind of training.

\section{Research limitations/ implications}

The article gives a general direction for the development of a consulting methodology and the education of consultants. Further research on consulting practices and repertoires is necessary to explore this direction.

\section{Practical implications}

The paper concludes that the value of phase-models as a standard is limited. Therefore, branch organizations, consulting firms and corporate universities should not focus their professionalization and training activities on these standardized methods. 


\section{What is original/ value of the paper}

Little work has been done yet on the relation between professionalization, methods, and training in management consulting, and no earlier publication has studied this topic quantitatively.

Keywords: professionalization, management consulting, phase-models, competence, knowledge management, professional training.

\section{Introduction}

The management consulting industry has grown enormously, especially during the last decade. In 1988, about 100,000 people worldwide were estimated to work full-time as management consultants (The Economist, 1988). In 1998, the top 3 consulting firms alone already employed more than a 100,000 consultants (Financial Times, 2000). In 2006, the numbers are still higher. The management consulting industry has also become more heterogeneous. It now comprises a broad range of specialisms, which are offered by a wide variety of consulting firms, ranging from very small to very big and from specialized to all-round. Some of these have been in management consulting for about a century, while others entered management consulting more recently from fields such as accountancy and ICT, or from industry, as outsourced internal consulting departments. The consulting field changes constantly. Many established consulting firms are involved in the formation of strategic alliances, mergers, and take-overs. Big consulting firms grow bigger every year, and because of the low entry barriers (Clark, 1995) - "the only real requirement for being a consultant is six dollars for business cards" (Gilley and Eggland, 1989, p.180) new consulting firms are established every day, resulting in a growing number of small firms.

The growth and increased heterogeneity of the management consulting business has reduced its transparency, for clients and for consultants themselves. Who is good and who is a charlatan? Consulting firms try to enhance transparency for clients through a better marketing of their services (Kaas and Schade, 1995) and through a professionalization of their work. Professionalization activities, carried out at the level of individual consulting firms as well as on the level of the occupational group, are meant to enhance the competence of consultants, i.e. their ability to perform to recognized standards (Jessup, 1991), and to effectuate a demarcation between competent consultants on the one hand and juniors, amateurs, or snake-oil-salesmen on the other.

One of the key professionalization activities concerns the establishment of a methodology, as part of a common body of knowledge. A methodology, 
mostly understood as a phase-model or a prescribed set of steps, can, when it is shared among the members of a consulting firm or among the whole occupational group, be a valuable means for professionalization, since it can serve as an occupational standard (Marshall, 1997) for training juniors, knowledge accumulation, and the evaluation of consulting work. For this reason, individual consulting companies, corporate universities, and branch organizations have done considerable work on the establishment of shared phase-model methodologies (ICMCI, 1999; Hansen et al, 1999).

The question this article addresses is whether this focus on the construction of phase-model methodologies is sensible. In order to be effective as a standard for training and evaluation, a methodology should 'capture' the competence of consulting work. It should provide a standard for good practice and reflect what the professionals in the field consider competent behavior. To address this issue, an empirical study has been carried out to explore management consulting practices and the actual role of phase-models in consulting work. This article presents the results of this study, investigates the possibilities of a phase-model methodology, and discusses its potential role in the professionalization of management consultants.

\section{Professionalization and management consulting}

The discussions on the professionalization of management consulting have taken two main routes. The first focuses on the question whether or not management consulting is a profession and can effectuate a demarcation between professional and non-professional consultants. The second route is more pragmatic, focusing on the enhancement of the competence of consultants, regardless of the success of the occupational group to claim a professional status.

In the first route of discussion, branch organizations have participated massively by claiming that management consulting is a profession like any other, only somewhat younger (e.g. ICMCI, 1999). It may not be full-grown yet, but it is on its way to maturity, partly thanks to professionalization efforts such as the establishment of shared phase-model methodologies. This claim has been contested by several authors, on the basis of a comparison of management consulting with well-established professions, in particular the medical or legal profession (Kieser, 1998; Van Baalen, 2000). According to these authors, a fully developed profession meets certain characteristics that management consulting fails to meet. A profession has successfully established jurisdiction over an area of working life and controls knowledge and its application within that area (Abbot, 1988). Practice is restricted to a well- 
demarcated group of practitioners, which is protected by government (Johnson, 1972). Candidate-practitioners are to go through uniform professional education and receive a certification before they are allowed to practice. A branch association, of which membership is obligatory, safeguands and improves the competence of its members and maintains the integrity of their conduct (Wilensky, 1964; Hughes, 1963). In the field of management consulting, jurisdiction is claimed, professional training, certificates, bodies of knowledge, branch organizations with regulatory power, and codes of conduct exist. But according to the critics, management consulting does not measure up to the ideal, or idealized (Abbott, 1988) picture of a full profession as sketched above. In management consulting, the work over which the profession is supposed to establish its jurisdiction is open to successful counter-claims and invasions by other professions or occupational groups such as managers, accountants and ICT-experts. There is no obligation to follow a professional training, to become a member of a branch organization, or to acquire certification. Nonparticipation in professionalization activities is not officially sanctioned by government. A further shortcoming, which is particularly relevant in the light of this paper, is that the body of consulting knowledge, including its methodologies, is not considered valid and shared enough to form a solid basis for uniform professional training, accreditation, and the evaluation of competent behavior (Berry and Oakley, 1994; Kubr, 1996; Kieser, 1998; Fincham, 1999).

For many consulting firms, the relevance of the above debate about the professional status of management consulting seems to be overtaken by their apparent success. Strong firms have emerged that do not really need branch organizations and their bodies of knowledge, education, certifications, codes of conduct, and a professional status of the occupational group as a whole to train and evaluate their employees and to convince their clients of their employees' competence. Their discussions about the professionalization of consulting work focus on the improvement of the competence and knowledge resources of their employees, as a means to enhance their competitiveness. These activities may include the writing of corporate handbooks with core values and standard operating procedures for formulating plans of approach and phasing projects. Some consultancies have established courses or 'corporate universities' to train their consultants (cf. Rademakers, 2005), and have developed databases or expert centers to provide them with expertise (Reimus, 1996). 'Knowledge management' is the term often used to denote these kinds of professionalization activities. In the context of knowledge management, phase-model methodologies may play an important role (Hansen et al., 1999), 
but then to give an individual firm a competitive advantage and not to professionalize the whole occupational group.

\section{Methodology}

To explore the ways of working of management consultants empirically, a survey was conducted among Dutch management consultants. The survey was sent to all subscribers of the magazine Management Consultant, in cooperation with the company that publishes the magazine. The list of subscribers comprises the active members of the Ooa, the Dutch national association of management consultants, but also retired members and other people with a professional interest in management consulting. In some cases, the magazine, and thus the survey, was sent to consulting firms rather than to individual consultants, who did the internal distribution themselves. In total, approximately 2500 surveys were sent, of which about 1000 were sent to active members of the $\mathrm{O}$ oa.

Of the 2500 distributed surveys, 279 were filled in and returned. This is a response-rate of about 11\%, a number that, according to a survey expert at the publishing company, is not unusual for surveys among management consultants. But because of the 'polluted' address-list that has been used, the response-rate in the actual target group of active senior management consultants is probably much higher, although no accurate estimate can be made with the available information. The group of respondents is in general senior and experienced. Only $6 \%$ of the respondents consist of junior consultants, and only 10\% have less than 3 years experience as a consultant. The others are more senior and experienced. Of the respondents, $62 \%$ even have more than 10 years experience and $44 \%$ hold a management-position in a consulting firm. At least $75 \%$ of the respondents have received an academic education, at least $8 \%$ have a Ph.D., and about 20\% have received specialized postgraduate education in management consulting. The senionity of the respondents is important for this study, because this seniority implies that the respondents have had the time to develop their own way of working, which requires ample experience. Besides, they have had the opportunity to internalize the rules of competent practice, also because they are a member of one of the branch organizations. The study assumes that, in general, the way of working of the respondents reflects competent practice, or at least that the number of respondents that would be considered incompetent by their colleagues is minimal.

With only a few exceptions, the respondents work as external consultants with a consulting firm. As a group, they cover all kinds of possible firms: big and 
medium-sized international and national firms, as well as small firms and selfemployed consultants. They also cover different fields of consulting, including organizational change, strategic management, HRM, ICT, quality management and training \& education. This safeguards the sample from a potential firm, or field bias.

\section{An exploration of management consulting work}

How do management consultants work? In general terms, three typical ways of working can be distinguished: a fixed way, a variable way and a case-based way. Consultants with a fixed way of working have a standardized generic method, a phase-model filled with 'content matter', which they use in all their projects. Consultants with a variable way of working do not follow a standardized generic method, but tailor their actions to specific situations. In principle, they could do something completely different every time, depending on, among other things, the problem at hand, the wishes of their clients and the contingencies in the process. Consultants with a case-based way of working do not have a standardized generic method, but they explicitly reuse generic elements from 'old' cases, such as standard models or solutions, which they adapt to new situations. Fixed, variable and case-based ways of working do not exclude each other though. So in the survey, respondents were asked to what extent they considered their way of working as fixed, variable, or case-based. The results are shown in figure 1.

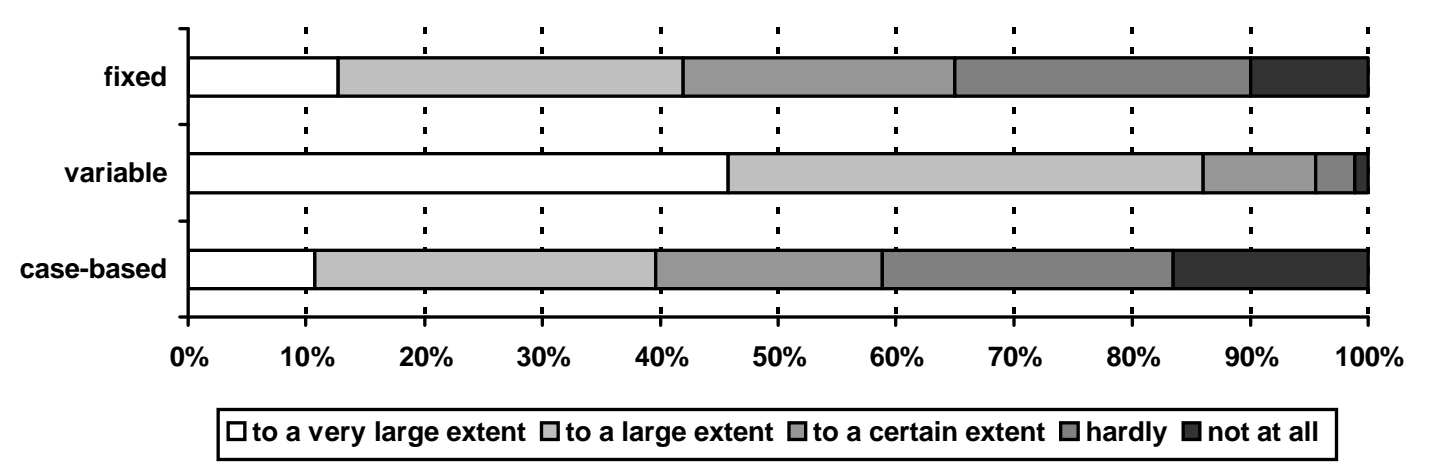

Figure 1: The extent to which approaches are fixed, variable, or case-based.

Most respondents considered their way of working to a large or very large extent variable, adapted to the specific situation. Only $4 \%$ said to have an approach that varies hardly or not at all. Some respondents commented that management consulting projects should always be tailored to the situation. This does not imply, however, that consultants have no fixed or case-based elements 
in their way of working. Respectively $42 \%$ and $40 \%$ of the respondents called their approach to a large or very large extent fixed or case-based. And further analysis shows that only $8 \%$ of the respondents do not have any fixed or casebased elements at all. A highly variable approach does not mean, apparently, that consultants do something completely different every time. Their way of working has generic and reusable elements, but these are always adapted to concrete situations. In the following sections, the fixed, variable, and casebased aspects of consulting work will be further explored.

\section{Fixed aspects of management consulting work}

Of the respondents, $42 \%$ considered their way of working to a large or very large extent as fixed (see figure 1). This section explores the fixed aspects of management consulting approaches, in particular the content and use of phasemodels. Of the respondents, $64 \%$ said they use an explicit phase-model in their consulting work. In the survey, these respondents were asked to mark whether their phase-model contained the phases of the problem solving cycle or regulative cycle (Lipshitz and Bar Ilan, 1996; Van Strien, 1997; Van Aken, 2004), which is assumed to be a basic figure for phase-models. Table I shows the results.

\begin{tabular}{|l|l|l|l|}
\hline Phases of the problem solving cycle & Yes & No & Not filled in \\
\hline Problem clarification & $95 \%$ & $3 \%$ & $2 \%$ \\
\hline Diagnosis & $92 \%$ & $5 \%$ & $3 \%$ \\
\hline Solution generation & $82 \%$ & $15 \%$ & $3 \%$ \\
\hline Testing & $58 \%$ & $33 \%$ & $9 \%$ \\
\hline Implementation & $81 \%$ & $15 \%$ & $4 \%$ \\
\hline Evaluation & $78 \%$ & $17 \%$ & $5 \%$ \\
\hline
\end{tabular}

Table I: Occurrence of phases of the problem solving cycle in the phase-models of the responding consultants.

The data show that clarification and diagnostic phases are present in almost all phase-models, that solution generation, implementation and evaluation phases are present in about $80 \%$ of the models, and that a testing phase is present in almost $60 \%$. Overall, the problem solving cycle appears to correspond fairly well with the phase-models that consultants use in practice.

What are the functions of these phase-models (Werr, 1999; Visscher, 2001)? First, phase-models have a cognitive function. They give consultants guidance and something to hold on to in their work. Second, phase-models have an educational function. They can be used to educate junior consultants. Phasemodels guide inexperienced consultants and help them to do a kind of job. 
These are internal functions of phase-models, which are considered primary by methodologists. Phase-models also have a social function, as a means to communicate to clients what a consultant does and will do in their organization. In addition, phase-models have a managerial function. They can be used as tools for project-management, to place milestones at the end of phases and to monitor the progress. These are external functions of phasemodels. In the survey, the respondents were asked to what extent they used their phase-model for these cognitive, social, managerial, and educational purposes. Figure 2 shows the results.

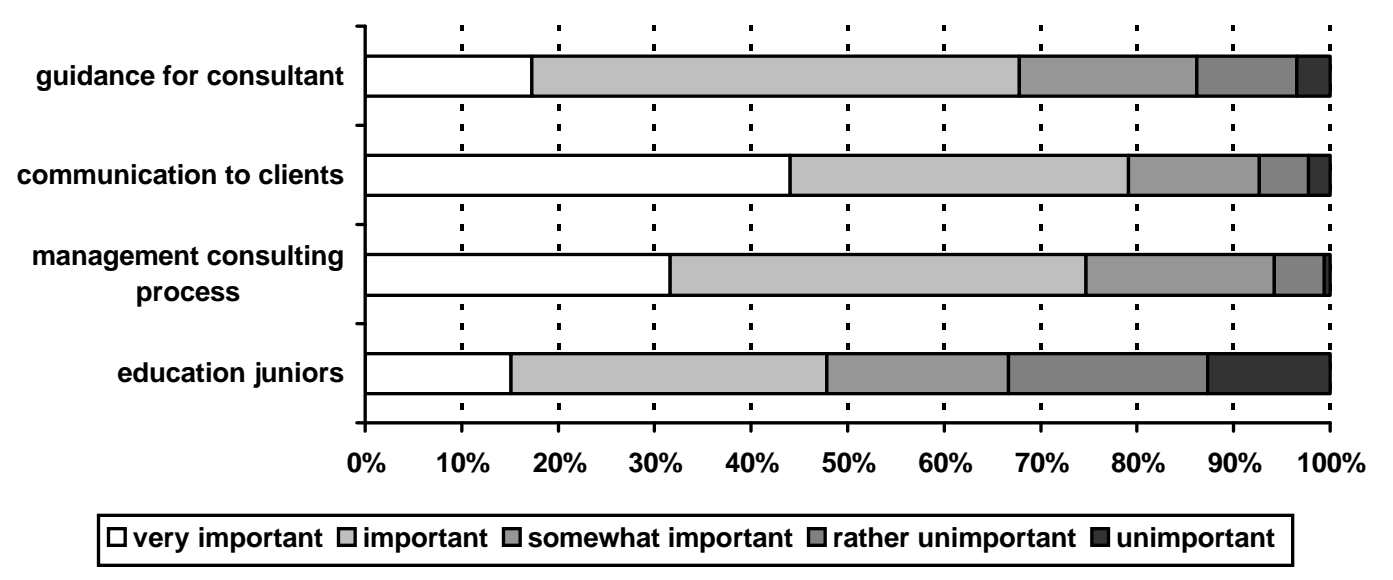

Figure 2: The functions of phase-models.

The social function was considered most important, followed by the managerial, cognitive, and educational functions respectively. The external functions of phase-models were regarded as more important than the internal, methodological functions. This is not the case for all respondents though. A minority valued internal functions over the external. If the cognitive and social function are compared, $16 \%$ of respondents with phase-models thought the cognitive function more important than the social function, while $43 \%$ saw it the other way around.

Phase-models may be followed strictly or they may be applied flexibly, tailored to the specific situations in which they are used. Consultants may skip phases in their models to make shortcuts, combine phases, or switch them. In the survey, respondents were asked how often they skip, combine or switch. Figure 3 shows the results. 


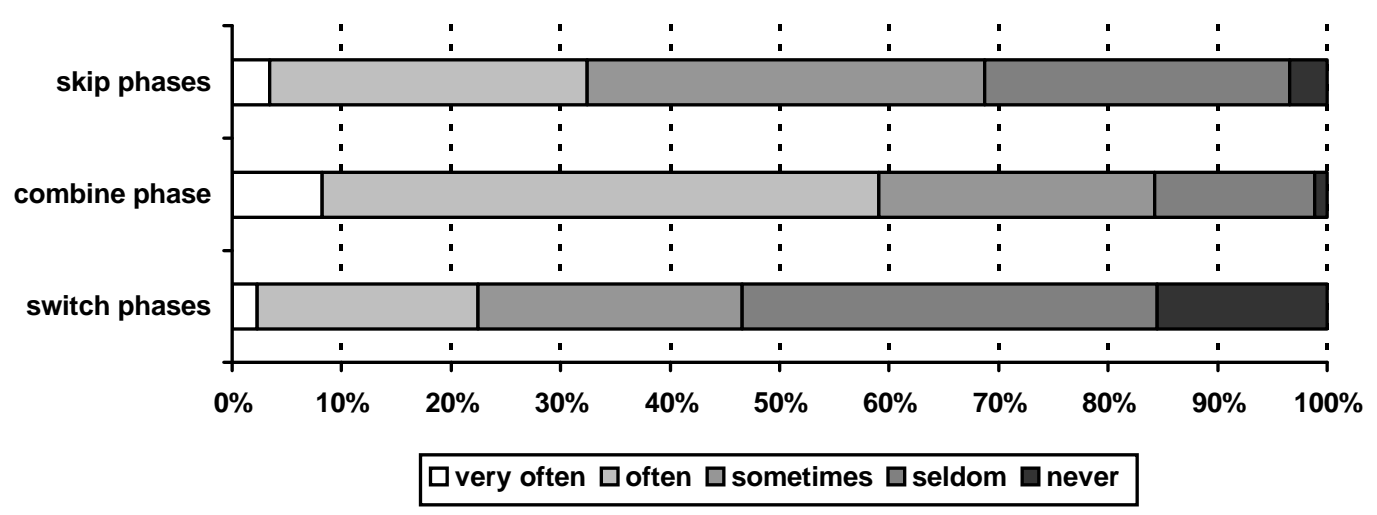

Figure 3: Skipping, combining and switching phases in the use of phase-models.

The data show that a minority of the respondents uses their phase-models in a very strict way. Most consultants show some flexibility in the application of their models, especially in combining phases. This fits with the conclusion that most consultants considered their way of working highly variable and situationspecific. To get an idea of how consultants adapt their phase-models, respondents were asked which phases of their models they skip, combine or switch. Table II shows the results concerning the phases of the problem solving cycle.

\begin{tabular}{|l|l|l|l|}
\hline Phases of the problem solving cycle & Skip & Combine & Switch \\
\hline Problem clarification & $6 \%$ & $39 \%$ & $5 \%$ \\
\hline Diagnosis & $6 \%$ & $45 \%$ & $5 \%$ \\
\hline Solution generation & $2 \%$ & $16 \%$ & $12 \%$ \\
\hline Testing & $17 \%$ & $20 \%$ & $9 \%$ \\
\hline Implementation & $13 \%$ & $18 \%$ & $7 \%$ \\
\hline Evaluation & $14 \%$ & $6 \%$ & $2 \%$ \\
\hline
\end{tabular}

Table II: Skipping, combining, and switching phases.

The data indicate that the problem clarification and diagnostic phases are rarely skipped or switched, but often combined, mostly with each other. In case of combination, consultants probably need a more thorough analysis to shed light on the problem. The solution generation is almost never skipped, but in some cases switched or combined, especially with the implementation and testing phases. This indicates a way of working in which design, implementation and testing are interwoven in an experimental, learning-by-doing process. The regular combination of testing with other phases may also explain the relatively frequent absence of a testing phase in phase-models (see table II). The absence of an explicit phase does not necessarily mean that a consultant does not test 
his or her solutions, since tests can be an integral part of the other phases. Implementation, testing, and evaluation are sometimes skipped, probably when the consulting project ends with recommendations, and does not include the implementation. Some consultants remarked that the skipping, combining, or switching of phases depends on the situation. According to them, there is not much fixedness in the flexible use of phase-models.

\section{Variable aspects of management consulting work}

Of the responding consultants, $86 \%$ considered their way of working to a large or very large extent as being variable and situation-specific (see figure 1). But what is situation-specific? 'The situation' is an ample and comprehensive term. To which dimensions of a situation do consultants adapt their way of working? In the survey, respondents were asked to mark to what extent they adapt their way of working to three given dimensions, viz. the characteristics of the content of the project, the wishes of their clients, and the actual course of the events in the consulting process. Figure 4 shows the results.

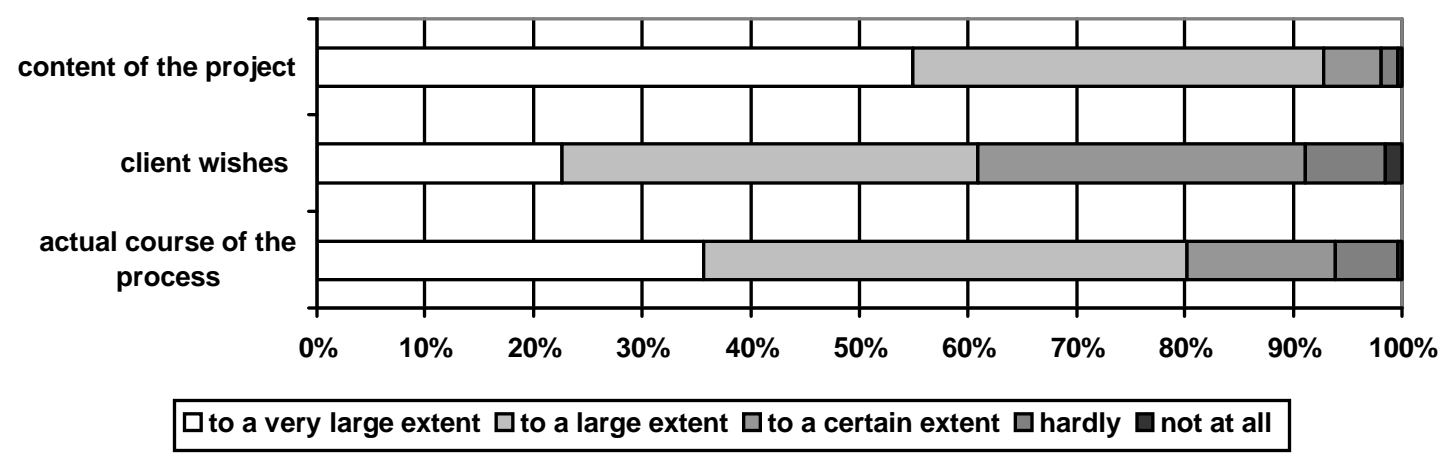

Figure 4: Dimensions of situation-specific consulting

All three dimensions were considered important, but the 'project' dimension was seen as most important, followed by the 'process' and the 'client' dimension. Almost all consultants adapt their way of working to the content of the problem at hand to a large or very large extent. Apparently, only very few consultants considered themselves to be working in problem situations of one kind or thought that they possess a universal recipe for all kinds of problems. The actual course of the project was also considered an important or very important dimension by most consultants. This implies that consulting processes are often seen as uncertain and difficult to predict, and that consultants shape their way of working along the way. The wishes of the client 
are important, too, although a considerable group of respondents does not adapt their way of working to them to a large or very large extent. These consultants probably considered their way of working a part of their expertise or professionalism, and did not think their clients competent enough to accept major alterations.

In the survey, respondents could mention other factors to which they appreciably adapt their way of working. All together, they mentioned 274 factors, some elaborating the given dimensions, others adding new dimensions. The factors have been clustered and categorized. They are presented in table III. The numbers in brackets indicate how many respondents mentioned a given factor.

\begin{tabular}{|l|l|}
\hline Dimensions & In particular, ... \\
\hline Project (51) & $\begin{array}{l}\text { The availability of time and money (24), the history of the project (5), the feasibility of the } \\
\text { project (5), the gravity and escalation of the situation (4), the 'real' problem (4), the } \\
\text { complexity of the project (2), the opportunities in the project for the consultant to learn } \\
\text { something (2), the similarity to other projects (1), the abstraction of the project (1), and } \\
\text { the project in general (2). }\end{array}$ \\
\hline Client (50) & $\begin{array}{l}\text { The client's quality and strength (14), the relation between the client and the consultant } \\
(11), \text { the client's commitment (8), wishes and expectations (6), acceptation of the } \\
\text { consultant (5), attitude and personality (3), the wishes and opinions of stakeholders (2), } \\
\text { and the client's earlier experiences with consultants (1). }\end{array}$ \\
\hline Process (19) & $\begin{array}{l}\text { The occurring resistance (6), the outcomes of tests and other formative evaluations (3), } \\
\text { new ideas and progressive insight (3), unexpected events (2), all kinds of upcoming } \\
\text { opportunities (2), changing client wishes (1), and the process in general (2). }\end{array}$ \\
\hline Client organization (68) & $\begin{array}{l}\text { The commitment and quality of the people in the organization (16), the organizational } \\
\text { culture (11), politics (9), structure and scale (4), the change potential in the organization } \\
(4), \text { its developmental stage (3), its atmosphere (2), the branch in which it is active (2), } \\
\text { the need for communication (2), the manageability of the organization (1), its earlier } \\
\text { experiences with consultants (1), and the client organization in general (13). }\end{array}$ \\
\hline Consultant (48) & $\begin{array}{l}\text { The consultant's personal values, opinions, and style (19), the characteristics of the } \\
\text { consulting team (9), the busyness and the ideas in the consultancy firm (6), the } \\
\text { consultant's role (6), knowledge and skills (5), mood (2), and reputation (1). }\end{array}$ \\
\hline Environment (12) & $\begin{array}{l}\text { The developments in the market-environment (3), macro-environment (3), publicity (1), } \\
\text { trade-unions (1), and the environment in general (4) }\end{array}$ \\
\hline
\end{tabular}

Table III: Dimensions of situation specific consulting.

The list is long and varied. There are various dimensions relating to the project, the client and the process. Furthermore, factors that have to do with the environment, and in particular with consultants themselves and the client organization, may influence the way of working of consultants in specific situations.

Case-based aspects of management consulting work

Of the respondents, $40 \%$ considered their way of working to a lange or very large extent case-based (see figure 1). Case-based ways of working can be 
supported by databases. In the survey, respondents were asked how often they use databases with examples and databases with benchmarks. Figure 5 shows the results.

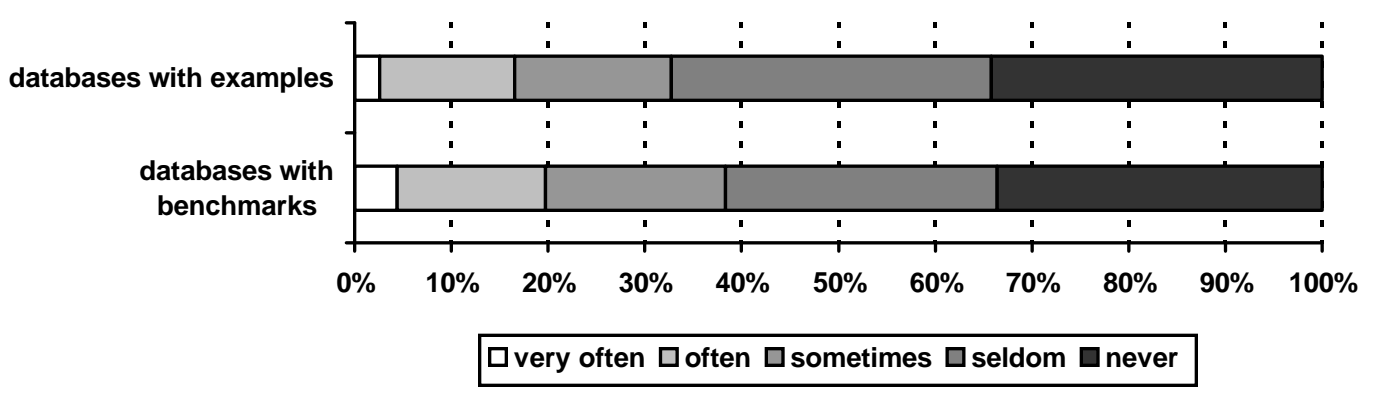

Figure 5: The use of databases with examples and with benchmarks.

The number of consultants that uses databases often or very often is about half the number of consultants who say they work case-based to a large or very large extent. Apparently, the other half stores 'cases' in different ways. They may have personal archives or just store their experiences in their heads. These media have the disadvantage that their content is much more difficult to share. An advantage is that the need for the codification of experiences is minimal.

\section{Developing a way of working}

The preceding sections have explored the fixed, variable and case-based aspects of the ways consultants work. This section investigates the genesis of these ways of consulting. From which sources do consultants gather the elements that constitute their way of working? In the survey, six sources were given. A first source is the consultants' reflection on their own consulting practice (cf. Schön, 1983). They can do this individually or collectively, together with their colleagues. Consultants can also copy things from their colleagues, especially if they have a mentor or can work with more experienced colleagues who can give training-on-the-job. A further source is their education in a formal setting, at universities, in postgraduate courses, or in specific management consulting courses. In these settings, skills and knowledge that are articulated on the professional level can be transferred to individual consultants. And finally, of course, literature can be a source. Consultants can adopt methods that have been described in literature, or they can use it as a source of inspiration for the development of their own way of working. In the survey, the respondents marked to what extent they used these sources to develop their way of working. Figure 6 shows the results. The respondents also mentioned other sources, 
such as their clients, their juniors, the international standards of their firm, and literature outside the field of management.

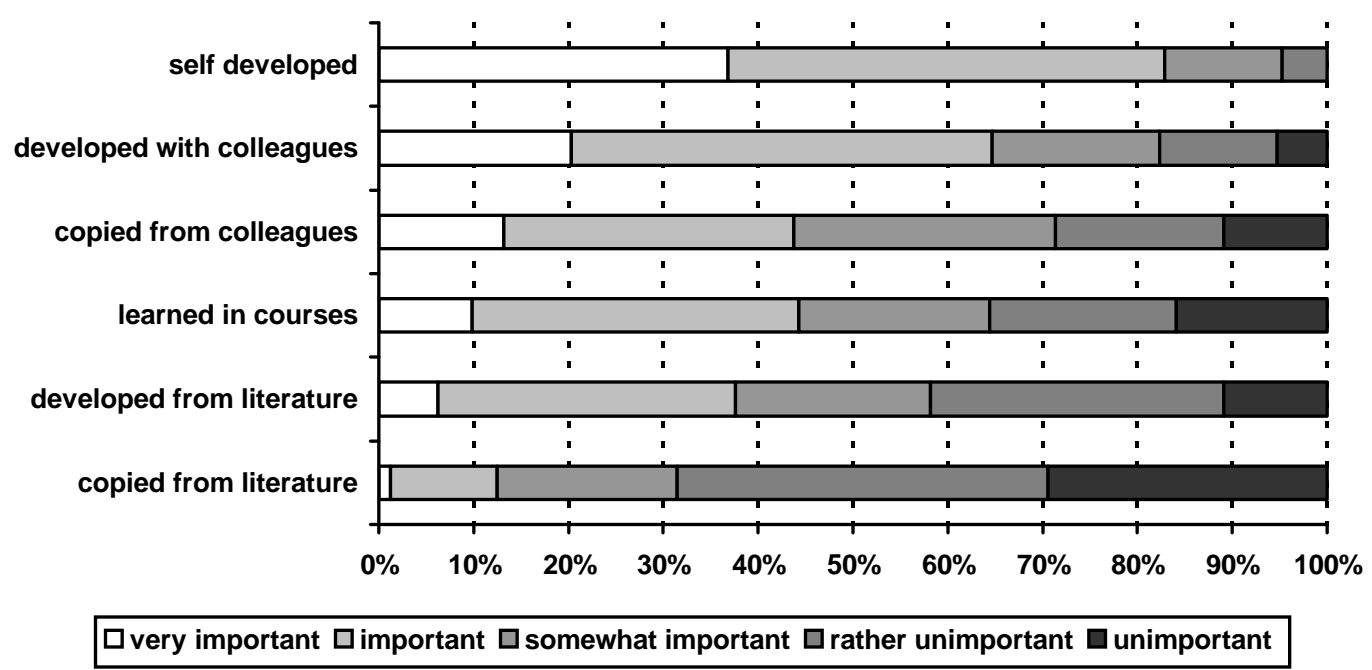

Figure 6: The importance of different sources for repertoire building.

There is a clear ranking. D eveloping a way of working was most importantly done by way of the individual reflections of consultants, while copying from literature was considered the least important. It appears to be more an individual activity than a collective or professional activity. Besides, the active ways of development were considered more important than the receptive ways. Consulting skills are only partly articulated on the professional level, and can only to some extent be acquired through formal education and literature. Learning-by-doing in concrete projects, in interaction with clients and colleagues, were in general considered more important.

\section{Conclusions and discussion}

The purposes of this article were to explore the ways of working of management consultants and the possibilities and potentials of a shared and standardized consulting methodology. In particular, the question is whether consultants follow phase-models, and which role a phase-model methodology can play in the professionalization of consulting work as a standard for training and evaluation. The survey data indicate that consultants generally do not follow phase-models. Although there is a small group of consultants who said they follow phase-models strictly, use them predominantly for methodological functions, and have a largely codified way of working with many generic and reusable elements, most consultants appear to consider their way of working as highly variable and situation-specific. Most consultants tailor their actions to 
the kind of project, the wishes of their clients, the contingencies of the process, and a whole range of other factors. These contingencies, which are thought to be essential for good consulting work, cannot be covered by a fixed series of steps. Of course, a sophisticated phase-model might, in principle, incorporate some of the contingency factors, such as the branch in which an organization is active or its developmental stage, but not all relevant factors. Some factors that are mentioned, such as the consultant's mood, the history of the project, and 'unexpected events', are impossible to incorporate in any phase-model.

That consulting work is in general not 'following phase-models' does not mean that consultants do not have phase-models, though. Many consultants have and use them. However, the external functions of phase-models, communication and project-management, are generally considered more important than the internal, methodological functions of guiding practitioners and educating novices. Phase-models may be followed to some extent, but then flexibly, by combining, skipping, or switching steps. They are often altered to match the situation. This frequent deviation from the 'official' order would be an anomaly from the 'consulting as following phase-models' perspective. One could wonder why consultants do not make more accurate and precise phase-models, which do not ask for reparation so often. The reason is that phase-models are not primarily meant to be strictly followed, and that more accuracy and precision does not necessarily improve their value. It is a tool, which may have several functions in the hands of a competent consultant. Improving the precision and accuracy of that tool might enhance its function as a guideline, but hamper its function as a medium for communication and projectmanagement.

In general, consultants appear to be bricoleurs (Lévi-Strauss, 1966; Weick, 1993). They have broad repertoires from which they assemble their way of working in a concrete situation. Phase-models may be an element of such a repertoire, just as databases and all sorts of 'uncodified' experiences. A repertoire is most importantly built through the consultant's reflection on his or her own experiences. Management literature, which is full of phase-models and other models that consultants might use, was considered a relatively unimportant source. It may be a source of inspiration, but not one to copy from. To a large extent, management consulting has to be learned in practice, in concrete management consulting projects. It is not unthinkable, though, that through the ongoing improvement of tools for knowledge sharing, the role of codified knowledge in consulting repertoires will increase in the future, in particular to facilitate case-based working. 
The training of junior management consultants may still start with teaching them a standard methodology, developed by a branch organization or corporate university, to be used to tackle textbook problems. But this methodology should not be applied as a standard for a way of working in practice. Consultants should learn how to situationalize methodologies, by specifying, changing, and possibly discarding them on-the-spot, for the benefit of a specific consulting project. The competence of consultants shows in their ability to adapt standard ways of working to specific contexts, not in their ability to make specific situations fit a standard way of working.

\section{References}

Abbot, A. (1988), The system of professions: A n essay on the division of ex pert labor, The University of Chicago Press, Chicago.

Berry, A, and K. Oakley, "Consultancies: agents of organizational development: Part II", L eadership \& O rganization D evelopment Journal, Vol 15 No 1, pp. 13-21. Clark, T. (1995), Managing consultants: C onsultancy as the management of impressions, Open University Press, Buckingham.

Financial Times (2000), "Consultants face future of change and uncertainty", 1012-1999.

Fincham, R. (1999), "Rhetorical narratives and the consultancy process", paper presented at the British Academy of Management Conference, Manchester.

Gilley, J.W. and S.A. Eggland (1989), Principles of human resource development, Addison-Wesley, Reading.

Hansen, M.T., N. Nohria and T. Tierney (1999), "What's your strategy for managing knowledge?" H arvard Business Review, March-A pril, pp. 106-116.

Hughes, E.C. (1963), "Professions", D aedalus, Vol 92, pp. 655-668.

ICMCI (1999), U niform body of knowledge.

Jessup, G. (1991), O utomes; N V Q and the emerging model of education and training, Falmer Press, London.

Johnson, T.J.J. (1972), Professions and power, The MacMillan Press, London.

Kaas, K.P. and C. Schade (1995), "Unternehmungsberater im Wettbewerb:

Eine empirische Untersuchung aus der Perspektive der neuen Institutionslehre [Management consultants in competition: An empirical study from a neo-institutional perspective]", Zeitschrift für Betriebswirtschaft, Vol 65 No 10, pp. 1067-1089.

Kieser, A. (1998), "Unternehmensberater: Händler in Problemen, Praktiken und Sinn [Management consultants; Traders in problems, practices and meaning]", in H. Glaser, E.F. Schröder, and A. von Werder (Eds.), O rganisation im W andel der Märkte, G abler, Wiesbaden, pp. 192-225. 
Kubr, M. (1996), Management consulting: A guide to the profession, ILO, Geneva, $3^{\text {rd }}$ edition.

Lévi-Strauss, C. (1966), The savage mind, Weidenfeld and Nicolson, London.

Lipshitz, R. and O. Bar-Ilan (1996), "How problems are solved: Reconsidering the phase theorem", Organizational Behavior and H uman D ecision Proesses, Vol 65 No 1, pp. 48-60.

Marshall, K. (1997), "O ccupational standards - a quality assurance mechanism for technical performance", Journal of W ork place L earning, Vol 9 No 6, pp.195198.

Rademakers, M. (2005), "Corporate universities: driving force of knowledge innovation", Journal of W ork place L earning, Vol 17 No 1/ 2, pp.130-136.

Reimus, B. (1996), Knowledge sharing within management consulting firms: Reports on how U.S.-based management onsultancies deploy technology, use groupware, and facilitate collaboration, Kennedy Publications, Fitzwilliam.

The E conomist (1988), "Survey", 13-2-1988, p.7.

Visscher, K. (2001), D esign methodology in management consulting, doctoral dissertation, University of Twente, Enschede.

Van Aken, J.E. (2004), "Management research based on the paradigm of the design sciences: The quest for field-tested and grounded technological rules", Journal of Management Studies, Vol 41 No 2, pp.219-246.

Van Baalen, P. (2000), "Legitimiteit, formele kennis en retoriek: De verleiding van de managementwetenschap in de professionalisering van het managementadvieswerk [Legitimacy, formal knowledge and rhetoric; The temptation of management science in the professionalization of management consulting", M \& 0 , Vol 54 No 5/ 6, pp. 37-61.

Van Strien, P.J. (1997), "Towards a methodology of psychological practice: The regulative cycle", Theory and Psychology, Vol 7, No 5, pp.683-700.

Weick, K.E. (1993), "Organizational redesign as improvisation”, in: G.P. Huber and W.H. Glick (Eds.), Organizational change and redesign: Ideas and insights for improving performanœ, Oxford University Press, New York, pp. 346-379.

Werr, A. (1999), The language of change: The roles of methods in the work of management consultants, doctoral dissertation, Stockholm School of Economics, Stockholm.

Wilensky, H.L. (1964), “The professionalization of everyone?”, A merican Journal of Sociology, Vol. 70, pp. 137-158. 